\title{
LA POESÍA SOCIAL COMO TESTIMONIO DEL HAMBRE. LA VOZ EJEMPLAR DE ÁNGELA FIGUERA ${ }^{1}$
}

\author{
SOCIAL POETRY AS A TESTIMONY OF HUNGER. \\ THE EXEMPLARY VOICE OF ÁNGELA FIGUERA
}

\author{
Carmen MEDINA PUERTA \\ Universitat de Lleida \\ cmedinap@filcef.udl.cat
}

\begin{abstract}
Resumen: La carestía alimentaria sufrida en España durante la posguerra (1939-1951) dejó una profunda marca en la sociedad española impregnando todas las esferas de la vida, entre ellas el arte. Para dar cuenta de ello nos proponemos analizar una serie de poemas de Ángela Figuera que tratan directamente el tema del hambre como trasunto de los cuidados y la domesticidad, ámbito al que se relegó a la mujer durante el franquismo. El propósito último de esta investigación es mostrar cómo a través de la literatura se puede acometer un análisis histórico que nos permita comprender nuestro pasado más reciente.
\end{abstract}

Palabras clave: Ángela Figuera. Poesía. Posguerra española. Hambre.

Abstract: The food shortage suffered in Spain during the postwar period

\footnotetext{
${ }^{1}$ Este trabajo forma parte del proyecto "Diversidad de género, masculinidad y cultura en España, Argentina y México” (FEM2015-69863-P MINECO-FEDER) del Ministerio de Economía, Industria y Competitividad de España.
} 
(1939-1951) left a deep mark in Spanish society permeating all spheres of life, including art. To give an account of this we propose to analyze a series of poems by Ángela Figuera that directly address the issue of hunger as a symptom of care and domesticity, an area that was relegated to women during the Franco regime. The ultimate purpose of this research is to show how a historical analysis can be undertaken through literature that allows us to understand our most recent past.

Key Words: Ángela Figuera. Poetry. Spanish Post-War. Hunger.

\section{INTRODUCCIÓN}

Ángela Figuera Aymerich (Bilbao, 1902-Madrid, 1984) es una de las voces imprescindibles de la literatura española contemporánea, no sólo por el valor testimonial de sus textos, localizados en la corriente de la poesía social de los años cincuenta, sino también por su alta calidad literaria. No obstante, y pese a tener una vasta producción, entre cuyos títulos destacan Mujer de barro (1948), El grito inútil (1952), Los días duros (1953) y Belleza cruel (1958), su legado artístico es apenas conocido. Los motivos que explicarían tal injusticia son fundamentalmente dos: la censura que sufrió su obra por cuestiones políticas (Blázquez Vilaplana, 2016: 40) y el hecho de ser mujer bajo el franquismo (Alonso Valero, 2016: 22). Sin embargo, estas adversidades no lograron silenciar a esta escritora sino que la denuncia de las mismas constituyó el motor principal de su escritura. Su poesía testimonia la doble condición de su insilio (Rodríguez Cacho, 2017: 310) como sujeto del bando perdedor y como mujer, al abordar un amplio espectro de temáticas (Alonso Valero, 2016: 31): la maternidad², único rol

${ }^{2}$ Cabe destacar que el tema de la maternidad en Ángela Figuera ha sido el motivo más estudiado por la crítica hasta el momento (Bosch, 1962; Arkinstall, 1997; Wilcox, 1992 y 1997; Robbins, 2000; Payeras Grau, 2002; Zabala, 2003; Reyzábal Rodríguez, 2009; Lara-Kuhlman, 2012; Abdelazim, 2017), no coincidiendo siempre en las mismas hipótesis y conclusiones: hay quienes ven en su reivindicación un sesgo reaccionario (Robbins, 
posible para el sujeto femenino durante el franquismo (Jurado Morales, 2014: 527), el estado de miseria que vivía el país, la carestía alimentaria y la muerte.

El propósito de este trabajo es analizar una serie de poemas de esta autora que tratan directamente el tema del hambre como reflejo de la sociedad española de posguerra ${ }^{3}$. A esto ha de añadirse que emprendemos tal tarea desde una perspectiva de género, ya que, a menudo, el hambre en Figuera aparece como un trasunto de los cuidados y la domesticidad, ámbito al que se relegó a la mujer durante el franquismo. Si bien los documentos sobre los que se fundamenta nuestra investigación son literarios, y por ello ficcionales, consideramos que por el valor testimonial y la voluntad realista característicos de la poesía social, constituyen un valioso material para comprender cómo desde la intrahistoria literaria se puede configurar una memoria colectiva alternativa a la oficial.

\section{LOS AÑOS DEL HAMBRE EN ESPAÑA (1939-1951)}

\subsection{La autarquía: El hambre como razón de Estado}

Podemos afirmar que si terrible fue el periodo bélico comprendido entre 1936 y 1939, más cruenta, por virulenta y larga, resultó la etapa de represión y carestía que le siguió (Abella, 1978: 51-54, 117). Los que sobrevivieron a aquellos tres dramáticos años aún tuvieron que sufrir un largo periodo de miseria y penuria extremas. Por más que Franco y sus ideólogos se obstinaran en denominarlo falazmente como los "años

2000) y quienes le atribuyen un valor emancipatorio (Arkinstall, 1997 y Zabala, 2003). Desde nuestra perspectiva, valoraremos esta temática como testimonio de una época y en última instancia como una reivindicación del género femenino.

${ }^{3}$ Por otra parte, cabe señalar que no hay estudios precedentes sobre el hambre en su lírica. No obstante, sí se han llevado a cabo numerosos e interesantísimos estudios sobre el hambre en otras autoras de la misma generación, como es el caso de Gloria Fuertes, entre los que podemos destacar: "Hambre y poesía: una breve biografía de Gloria Fuertes" (1993) de Brenda Cappuccio y "Pan y versos: hambre y subversión en la poesía de Gloria Fuertes" (2008) de Reyes Vila-Belda. 
triunfales" (Martín Gaite, 1987: 11), son recordados todavía hoy por muchos de los supervivientes como "los años del hambre" (Barranquero y Prieto, 2003: 89-90). Diferentes factores explicarían las causas que propiciaron la escasez de recursos materiales y la imposibilidad de la economía para suplir las necesidades básicas de la población española que sobrevivió al desastre (Abella, 1978: 122). En primer lugar, las consecuencias de la propia guerra. Todo conflicto bélico supone un importante desgaste económico y humano, pero además han de tenerse en cuenta las particularidades del contexto geopolítico en el que se desarrolló la contienda española y que justifican el estado de desamparo y aislamiento en que quedó el país. Cronológicamente, la Guerra Civil se localiza en el periodo a caballo entre las dos Guerras Mundiales ${ }^{4}$, lo que permite imaginar el estado de devastación general sufrido en toda Europa. A esto ha de añadirse el hecho de que las potencias del Eje, principales aliadas del bando golpista, vencedor de la Guerra Civil española, fueron las grandes derrotadas de ambos conflictos mundiales (Abella, 1978: 70-80; Martín Gaite, 1987: 11; Richards, 1999: 99).

De este modo encontramos que el país, con la figura del dictador Francisco Franco a la cabeza, se hallaba en una situación de desventaja en el marco político mundial, situación que fue utilizada, a su vez, como justificación para la implantación de un régimen político y económico fascista, conocido como autarquía ${ }^{5}$, que sumió, más si cabe, al país en un estado de miseria absoluta:

Laautarquía, entendida comouna expresión deultranacionalismo, rechazo del liberalismo, deseo de industrialización nacional, simpatía por las ideas fascistas y un modo de prepararse para desempeñar el papel que se deseaba interpretar en el conflicto mundial al lado de las potencias fascistas. Además, la autarquía

\footnotetext{
${ }^{4}$ Para un análisis más detenido de esta cuestión véanse Preston (2011) y Casanova (2013). ${ }^{5}$ Para una lectura más detenida de esta cuestión véase el capítulo "Política y economía de la autarquía” que Richards (1999) le dedica a este tema, así como Barciela (2003).
} 
encajaba muy bien con la creencia más general de que España debía aislarse política y culturalmente del mundo exterior. El sufrimiento físico y psicológico que creó esta segregación, en buena parte autoimpuesta, era considerado un castigo por los "pecados" de los españoles que había puesto en tela de juicio el sistema social de la España prerrepublicana. La autosuficiencia fue, sin duda alguna, un desastre para el pueblo español [...] La autarquía era considerada algo "técnico", "práctico" $y$ "espiritual". Desde el primer momento fue un elemento fundamental del programa totalizador que pretendia organizar la sociedad desde arriba (Richards, 1999: 100, 102).

En términos sociales y económicos el país se encontraba desolado tras el conflicto fratricida: los más de seis millones de fallecidos, las masas de población exiliadas, los destrozos ocasionados en miles de ciudades y pueblos de todo el territorio nacional, sin olvidar el estado generalizado de desnutrición. Pero si las condiciones materiales eran implacables, no eran menos las estrategias ideológicas desplegadas por el gobierno para dar respuesta a tal panorama de miseria y hambre. Uno de los mecanismos sobre los que se apoyó este nuevo régimen autárquico fue, precisamente, la proclamación celebratoria de esta derrota como una victoria colectiva. De este modo, la dictadura de Franco no sólo acalló las voces disonantes mediante la persecución y asesinato (Richards, 1999: 24-48) ${ }^{6}$, así como la prohibición a hacer referencia al estado de pobreza del país (Abella, 1978: 116; Martín Gaite, 1987: 5; Almodóvar, 2033: 257), sino que promulgó y

\footnotetext{
${ }^{6} \mathrm{~A}$ este respecto cabe referir unos versos de Ángela Figuera que hacen referencia al estado de desolación así como a la censura que se vivieron durante la posguerra: "Porque hoy, Señor, te hablo de esos muertos. / De los muertos más muertos, más hundidos; de los muertos del todo. / Pasaron muchos, pero muchos quedan en carne viva - suya- demorados [...] Otros, amordazada ya su boca/ con lodo espeso, gritan, gritan, gritan..." en "El barro humilde" (1999: 126). No podemos dejar de señalar los ecos de "Insomnio" de Hijos de la ira (1946: 15-16) de Dámaso Alonso que encontramos en este poema, como bien señalara Leopoldo de Luis (2000: 205-206).
} 
alabó las pérdidas cotidianas como logros sociales y morales, entre ellas el hambre (Martín Gaite, 1987: 16; Barranquero y Prieto, 2003: 68). Para esto se apoyó, además, en el discurso religioso, instaurando lo que se ha dado a conocer como nacionalcatolicismo (Richards, 1998: 53)7:

The way in which the combination of National-Catholic culture, social dislocation, and poverty fuelled a return to "primitivism" also forms part of this picture of reducing cultural resistances [...] Paradoxically, in spite of the evident contradiction between authoritarian Catholic, national-patriotic culture on the one hand and the pre-consumerist values of much 1940s popular culture on the other, because the former impeded or atrophied independent critical thouhght, there is a sense in which it can be said to have facilitated the uncritical assimilation of new, consumerist cultural values -under the later guise even of rebellion against regime puritanism, or in some cases against the seriousness of the opposition (Graham, 1996b: 242-243).

Finalmente, es preciso indicar que el verdadero objetivo del régimen autárquico impuesto durante la posguerra era el establecimiento de una radical división de la sociedad española entre vencedores y vencidos, bajo esta última categoría se englobaba a republicanos, demócratas, liberales y clase trabajadora. Para ello se sirvió de unas políticas basadas en la represión física, psicológica, económica y cultural que favorecieron el enriquecimiento de las élites dominantes a la vez que, mediante el control del abastecimiento de los bienes de primera necesidad, sumieron en la miseria a las clases más desfavorecidas (Graham, 1996a: 183; Richards, 1998: 24-26). Además, otra consecuencia directa de estas políticas fue la aparición de una fuerte economía sumergida, mediante mecanismos como el mercado negro y el estraperlo (Graham, 1996a: 186). Por último, cabe señalar que esta carestía alimentaria se prolongó durante más de

${ }^{7}$ Para una lectura más atenta véase Cuenca Toribio (2008). 
una década (Barranquero y Prieto, 2003: 65) y afectó, inevitablemente, a todas las esferas de la vida colectiva, entre ellas la literatura, cuestión que abordaremos más adelante.

\subsection{Ser mujer durante el franquismo: La alimentación y los cuidados como universo femenino}

Cabe ahora detenerse en cómo afectó esta problemática política y social al universo femenino y de qué manera se hizo más estrecha, si cabe, la relación entre alimentación, o más concretamente, la falta de víveres, conocida como racionamiento (Abella, 1978: 116-119; Martín Gaite, 1987: 5-6; Almodóvar, 2003: 233) y la condición femenina. Nos interesa profundizar en este aspecto porque tanto nuestro estudio como la poesía de Figuera no pueden entenderse sin una perspectiva de género (Robbins, 2000: 577; Rodríguez Núñez, 2001: 152; Zabala, 2003: 268; Lara-Kuhlman, 2012: 88)

La distinción de los roles genéricos, de por sí notable en un país subdesarrollado como España a principios del siglo XX, se radicalizó durante el franquismo, en gran medida debido a la influencia eclesiástica que condenó y suprimió las conquistas en materia de igualdad alcanzadas durante la Segunda República (Payeras Grau, 2008: 172; Jurado Morales, 2014: 527; Nash, 2015: 191) ${ }^{8}$. De este modo, el papel de la mujer en la posguerra española se vio limitado en la mayoría de los casos al de madre y cuidadora del hogar y, tal como hemos comentado con respecto al problema del hambre, la retórica religiosa del sufrimiento y del sacrificio personal se utilizó como mecanismo ideológico para fomentar esta función (Martín Gaite, 1987: 36; Barranquero y Prieto: 2003: 253; Jurado Morales, 2014: 537; Nash, 2015:193) ${ }^{9}$.

${ }^{8}$ Entre éstas cabe señalar: la abolición, mediante decreto, de la coeducación implantándo-
se en su lugar el conocido como Servicio Social obligatorio para las mujeres que desearan
obtener trabajo y la prohibición de poseer propiedades o de heredarlas (Martín Gaite,
1987: 17, 66, 42).
${ }^{9}$ Es preciso señalar muy brevemente que esta retórica influyó en todos los discursos, entre 
Por otra parte, es preciso señalar que el interés en que la mujer se dedicara en exclusividad al trabajo reproductivo ${ }^{10}$ promovido a través de la Sección Femenina, la propaganda cultural difundida en radios y revistas y los sermones religiosos lanzados desde los púlpitos (Martín Gaite, 1987: 140-151; Graham, 1996a: 182; Jurado Morales, 2014: 529), en realidad no sólo se debía a la moral católica y la ideología patriarcal del régimen franquista sino que también respondía a la necesidad del Estado de reducir el número de demandantes de empleo en un país sumido en la crisis y el paro (Martín Gaite, 1987: 32; Barranquero y Prieto, 2003: 254). A esto ha de añadirse el hecho de que tras la guerra la masa poblacional se vio enormemente reducida, con lo cual se indujo a la mujer a repoblar el país que se había desangrado y cumplir así su papel como reproductora de vida:

El cuerpo reproductor femenino era clave para frenar la degeneración nacional a través de un incremento de la natalidad [...] El pronatalismo franquista pretendia defender los intereses nacionales y la civilización occidental mediante la maternidad prolifica. Sin embargo, aunque estas políticas públicas pronatalistas afectaban directamente al cuerpo de las españolas,

ellos el poético (Rubio y Urrutia, en Luis: 2000: 84; Robbins, 2000: 576; Payeras Grau, 2002: 28-29). Baste recordar algunos títulos de las composiciones de los poetas de las décadas de los años 40 y 50: Cántico espiritual (1942) de Blas de Otero, Mujer sin Edén (1947) de Carmen Conde y los poemas "Presencia de Dios", "San Poeta labrador", "Me explico ante Dios" y "Niño-Dios" de Ángela Figuera (1999: 181-182, 246-247, 273, 286287). Si bien no nos detendremos en la utilización del discurso católico en la poesía de Ángela Figuera, para una lectura más atenta véase Arkinstall (2009: 85-139).

${ }^{10}$ Recurriremos a este concepto, basándonos en la teoría que la filósofa marxista Silvia Federici expone en Revolución en punto cero. Trabajo doméstico, reproducción y luchas feministas (2013), cuando hagamos referencia a aquellas tareas y labores que históricamente ha desempeñado la mujer, como son el dar a luz, el cuidado de los hijos y los ancianos, las tareas domésticas e incluso el acompañamiento y el apoyo afectivo, y por las que no ha recibido retribución económica. A continuación se ofrecen las palabras de Federici que justifican la conjunción de los términos "trabajo" y "reproductivo" sobre los que se asienta su teoría: "Hablo de trabajo 'reproductivo' [...] porque, desvelando su función en la reproducción de la fuerza de trabajo, se revelan las contradicciones inherentes a este trabajo" (2013: 165). 
ellas no tenían voz en su elaboración. En efecto, las mujeres quedaron politizadas a través de un destino común determinado por su capacidad reproductora. Con una maternidad impuesta, en la posguerra, fueron secuestradas por el interés del estado en promover el Cuerpo reproductor femenino como salvador de la patria y de la españolidad (Nash, 2015: 203).

A su vez, ha de precisarse que la función de estos futuros hijos no era otra que la de servir como fuerza de trabajo barata (Federici, 2013: 165). Por otra parte, recordemos que entre las medidas del régimen franquista para promocionar esta tarea reproductiva destacaron la Ley de Subsidio Familiar de 1938 que fomentaba las familias numerosas a través de pluses económicos, ofreciendo hasta 50 pesetas mensuales si se excedían los doce hijos y premios, fama incluida en la prensa local, y la Ley de Ayuda Familiar de 1946 que además penalizaba, mediante la sustracción del plus, a las esposas que desarrollaran un empleo remunerado (Graham 1996a: 184; Barranquero y Prieto: 2003: 254).

Ante esta petición estatal, y en relación a la literatura social, no quedaron calladas las poetas sociales de la época. Con su escritura ejercieron una función crítica de denuncia de esta doble explotación, la laboral y la reproductiva, en poemas como "Tener un hijo hoy" de Gloria Fuertes (1981b: 122), del que cabe señalar unos versos: “Tener un hijo hoy, / para echarle en la boca del cañón, / abandonarle en la puerta del Dolor [...] Tener un hijo hoy, / para que pase hambre y sol" o el maravilloso poema "Rebelión" de Ángela Figuera (1999: 143-144) que concentra todo lo hasta aquí expuesto:

Serán las madres las que digan: Basta.

Esas mujeres que acarrean siglos

de laboreo dócil, de paciencia, igual que vacas mansas y seguras que tristemente alumbran y consienten 
con un mugido largo y quejumbroso

el robo y sacrificio de su cría.

Serán las madres todas rehusando

ceder sus vientres al trabajo inútil

de concebir tan sólo hacia la fosa.

[...]

No más parir abeles y caínes.

[...]

¿Por qué suministrar carne con nervios

al agrio espino de alambradas,

bocas al hambre y ojos al espanto?

No obstante, aunque por ley se excluyó a la mujer del ámbito laboral, esto no significó que la mujer se liberara del trabajo. En muchos casos no sólo se ocupaba de las tareas del hogar sino que siguió ejerciendo un trabajo fuera de casa pero en peores condiciones que sus compañeros e incluso, en muchos casos, sin percibir una retribución económica, especialmente cuando realizaban tareas domésticas en casas ajenas donde, a cambio de sus servicios, solían recibir alimentos o asilo (Barranquero y Prieto, 2003: 262-263) ${ }^{11}$.

En este sentido, otro aspecto destacable es el hecho de que ante el panorama de pobreza y frente a la persecución ideológica contra la mano de obra femenina asalariada, la fuerza productiva de esta sufrió una polarización entre las tareas reproductivas no remuneradas de las perfectas casadas y los ángeles del hogar ${ }^{12}$, y la prostitución (Nash,

\footnotetext{
${ }^{11}$ Esta cuestión también ha sido reflejada en la literatura, cabe destacar, especialmente, la novela La plaza del diamante (1962) de Mercè Rodoreda.

${ }^{12}$ Por servirnos de metáforas literarias hemos utilizado los títulos de las novelas: La perfecta casada (1584) de Fray Luis de León, a partir de la cual pretendía establecer una norma de conducta femenina durante el reinado de Felipe II, y El ángel del hogar (1881) de María Pilar Sinúes que elaboró un prototipo de mujer modélica que se extendió durante el Romanticismo español. Estos tópicos literarios se asentaron fuertemente en la literatura
} 
2015: 194) $)^{13}$, actividad que estuvo permitida que se ejerciera en las casas de tolerancia hasta 1956 (Graham, 1996a: 189-191). Esta radical división impuesta al rol femenino da cuenta, de nuevo, del carácter contradictorio que definió al régimen franquista durante sus más de cuarenta años de imposición.

\section{LA REALIDAD ATRAVESANDO LA LITERATURA O CÓMO LA LITERATURA DA CUENTA DE LA HISTORIA: EL HAMBRE COMO TEMÁTICA FICCIONAL}

Darcuenta de la realidad, ser testimonio útil para los contemporáneos pero también para el lector del futuro, acceder a un público lector amplio, narrar anécdotas cotidianas capaces de trascender la vivencia personal, ser "vocero" del pueblo, en definitiva, era lo que se propuso el y la poeta social de los años cincuenta (García, 2012: 25), entre ellos Ángela Figuera ${ }^{14}$.

\footnotetext{
$\mathrm{y}$, sobre todo, en la sociedad española y han perdurado a lo largo de los siglos, como bien demuestra el trabajo de Aldaraca (1992). Con respecto a la contemporaneidad podemos señalar que, tras la incipiente liberación de la mujer que supuso la II República, ambos códigos de conducta tuvieron un exitoso "revival" durante la posguerra (Martín Gaite, 1987: 40; Ugalde, 2007: 20-21 y 2009: 76; Jurado Morales, 2014: 540).

${ }^{13} \mathrm{Si}$ bien no nos detendremos en este aspecto que merece un estudio aparte, cabe destacar que se han llevado a cabo importantes estudios al respecto. Véanse el capítulo "Entre santa y santo, pared de cal y canto" que le dedica Martín Gaite (1987) y el monográfico de Núñez (2003), entre otros. Además de estos estudios históricos, contamos con algunos testimonios literarios fundamentales. En narrativa destacó el retrato realista de la prostitución que Cela acometió en La colmena (1951) y en poesía baste señalar como ejemplos algunos de los títulos que abordaron esta problemática; entre ellos destacan "Años triunfales" de Jaime Gil de Biedma (2006: 160), "Los sábados las prostitutas madrugan mucho para estar dispuestas" de Ángel González (2004: 210-212), "La arrepentida” (1981b: 64) y "24 de diciembre" (1981a: 290) dedicado "a una mujer de alterne (alias) Sor Telaraña del portal de Belén" de Gloria Fuertes y "La esquina", "Mujer en la esquina" y "Voz de mujer a Dios" de Angelina Gatell (en Conde, 1967: 184-185, 186-187, 188-189).

${ }^{14} \mathrm{Si}$ bien no nos detendremos a estudiar detenidamente a todos los autores, es preciso señalar algunos de los nombres ineludibles; entre ellos, Gabriel Celaya, Blas de Otero, José Hierro, Victoriano Crémer, Ángel González, Jaime Gil de Biedma, el propio Leopoldo de Luis, Gloria Fuertes, Angelina Gattell y María Beneyto.
} 
Se ha derramado mucha tinta para explicar cómo surgió la poesía social y cuáles fueron los presupuestos de esta búsqueda poética. No obstante, la aparición de esta poesía en España se vincula con un contexto histórico claro: la posguerra. A partir de 1939, fecha en que acaba la guerra civil española, España quedó escindida en dos, el bando de los vencedores y la mayoría social vencida. Estos avatares históricos repercutieron profundamente en la vida política y cultural del país:

Acabada la Guerra Civil, el problema de la cultura española, y particularmente la poesía, se vincula estrechamente con la situación general del país. Los cientos de miles de muertos en la contienda, los millones de personas traumatizadas por el horror o los anhelantes por el triunfo, son el sustrato emocional de las manifestaciones culturales a partir de 1939 hasta bien comenzada la posguerra (Rubio y Urrutia, en Luis, 2000: 53).

A continuación nos detendremos a estudiar algunos de los presupuestos más notables de la poesía social para tratar de dilucidar en qué medida se emparentan con la concepción poética de Figuera ${ }^{15}$. Así mismo también justificaremos por qué la estética social convirtió el tema del hambre en un asunto lírico de primer orden.

\subsection{Temáticas impuras vs. Temáticas puras}

Además de los años del hambre, los años de posguerra fueron también un periodo de reflexión acerca del papel social que debía desarrollar el arte y la poesía. De entre las pieles que adoptó tal problemática, la más destacada es, sin lugar a dudas, la interrogación constante sobre la pureza o impureza de la praxis estética. En nuestra geografía tal dicotomía tenía precedentes. Si la poesía pura, cuyo máximo exponente era Juan Ramón

\footnotetext{
${ }^{15}$ Para una lectura más detenida de las características y fundamentos teóricos de la poesía social veánse Ascunce (1997), Luis (2000) y García (2012).
} 
Jiménez, se ocupaba de lo puro, lo eterno o lo bello, la poesía impura, preconizada por Neruda en Caballo verde para la poesía, debía, en palabras de Celaya, ocuparse del "barro, del calor animal, de la retórica y hasta de la política" (García, 2012: 24).

En esta línea, cabe destacar, la importancia que toma este tema en la poesía última de Miguel Hernández, especialmente en el poema titulado, justamente, "El hambre" (1979: 374-375) de El hombre acecha (1939). En él Hernández describe la atmósfera de la guerra a la vez que augura el clima inhóspito de una posguerra que él apenas llegaría a presenciar. Además, su maestría poética lo emparenta con los posteriores poetas sociales (Luis, 2000: 204-205; Rubio y Urrutia en Luis, 2000: 91; García, 2012: 239-281; Rodríguez Cacho, 2017: 308)

Con respecto a las generaciones de posguerra, esta radical división se produjo entre los poetas que publicaban en la revista Garcilaso, denominados, a su vez, garcilasistas, de los que cabe destacar a José García Nieto, Jesús Juan Garcés y Rafael Montesinos, como representantes de la poesía pura, y los que lo hicieron en la revista Espadaña; valga señalar la presencia de autores como Eugenio de Nora y Victoriano Crémer, que abogaban por una poesía rehumanizada (Rubio y Urrutia, en Luis 2000: 81-83, 93; Alonso Valero, 2017: 98) ${ }^{16}$.

En relación a la poesía de Figuera observamos, tal como han apuntado diferentes críticos (Payeras Grau, 2002: 27; Zabala, 2003: 250251), que la guerra supuso un punto de inflexión en el espectro de temáticas que abarcó su obra, cambiando los ejes temáticos de la inspiración poética y la felicidad materna de Mujer de barro (1948) y Soria pura (1949) por

\footnotetext{
${ }^{16} \mathrm{~A}$ este respecto cabe señalar que esta toma de postura aparece como temática de muchas de las composiciones de los poetas sociales. Entre algunos ejemplos véanse "Cartilla (poética)" de Blas de Otero (2013: 427) o "El cielo" de la propia Figuera (1999: 221-222), del que podemos recordar algunos versos: "Colegas queridísimos, estetas defensores / del pájaro y la rosa y el mundo está bien hecho / etcétera, y cantemos al cielo en primavera / porque es azul y estalla la gracia y poesía [...] Pero, amigos, decidme, por los clavos / de Cristo, por los clavos del hombre, ¿estáis seguros? / ¿Creéis que un bello cielo nos cubre todavía? [...] Pero es casi imposible. Pues yo no veo el cielo [...] No es posible encontrarlo a través de la efigie / coronada de gloria del tirano sargento".
} 
temas como la libertad de expresión, el miedo o la pobreza en Vencida por el ángel (1950), El grito inútil (1952), Los días duros (1953) y Belleza cruel (1958). A este respecto son también reveladoras las declaraciones de Figuera que encontramos en su poética para la antología Poesía social española contemporánea (1939-1968) de Leopoldo de Luis, donde da cuenta de su trayectoria lírica que se funde con su biografía y cómo la guerra impuso unos temas y un tono a su poesía:

Una primera poesía imitativa, vacilante, intimista y mala, sin duda alguna [...] De pronto, los tremendos golpes de nuestra guerra y la guerra mundial, la intimidad feliz se desgarra, el suelo se hunde, los sueños se quiebran, las perspectivas se transmutan y confunden entre la negrura del humo y la sangre. Entro en contacto con el odio, la codicia, la destrucción, la injusticia, la muerte innumerable, antinatural e ilícita. El hambre pisándonos los talones [...] Terminó la intima soledad del poeta. Porque también hay que escribirlo todo. El impulso primero de expresarse y crear belleza con la palabra es el mismo. Las circunstancias, no. Lo que he visto padecer, padeciéndolo, lo que sigo viendo, me acucia con exigencia imperiosa. Tengo que gritar contra ello y buscar algo que oponer al derrumbre [...] No me importa si mi poesía es, por lo circunstancial, por lo concreta e impura, perecedera. Si un solo hombre de mi tiempo se siente por ella comprendido y acompañado, consolado y estimulado, ya no habrá sido inútil (2000: 228-229).

De este modo podemos constatar cómo la temática del hambre fue una las más recurrentes de la lírica de Figuera, entre algunos de los poemas que lo corroboran podemos señalar: "Egoísmo" (1999: 12-122), del que cabe citar los versos: "Fuera, el naufragio; fuera el caos; fuera/ ese pavor, abierto como un pozo, / de las bocas que gritan / al hambre, al ruido, al odio, a la mentira, / al dolor, al misterio"; "Silencio" (1999: 149150) del que también podemos señalar los siguientes versos: "Y aunque 
grites el hambre y las madres robadas, / no habrá pan en las bocas ni los rotos regazos / serán llenos de nuevo con el peso del hijo" y el poema titulado "Carta abierta", remitida a "Jesús de Nazaret (Dios Hijo)", con dirección a "Cielo" (1999: 234-235), en la cual interroga a su interlocutor del siguiente modo: "No sé cómo andaría en aquel tiempo / lo de vivir del tajo y ser un pobre, / pero lo que es ahora es un milagro / mayor que el de los panes y los peces / para poner algo en la mesa y repartirlo / para que llegue a todos. Haz la prueba".

\subsection{Historicidad, autorreferencialidad y función testimonial}

Otra de las características definitorias de la poesía social es la historicidad, es decir, el afán por incardinarse y responder al momento histórico en el que el acontecimiento poético se localiza (García, 2012: 65). Si bien es cierto que esta fue una categoría central de este movimiento lírico, tenía ya algunos precedentes destacables, como es el caso de Antonio Machado y su concepción de rehumanización de la poesía (Luis, 2000: 31). Por otra parte, hemos de señalar que lo que se ha denominado como historizar va más allá de fechar los poemas o de localizarlos espacialmente, aunque muchos poetas van a servirse, además, de este recurso. En la poesía social encontramos numerosos poemas donde los poetas han fechado sus creaciones: "Yo doy todos mis versos por un hombre en paz. / Aquí tenéis, en carne y hueso, / mi última voluntad. / Bilbao, a once de abril, cincuenta y uno" de Blas de Otero (2013: 227) o el conocido poema de Ángel González: "Aquí Madrid, mil novecientos / cincuenta y cuatro: un hombre solo" (2004: 16) del libro Áspero mundo (1956). Recurso que utilizarán también las poetas, entre ellas Francisca Aguirre con el poema "Paisajes de papel" en el que declara: "Ser niño en el cuarenta y dos parecía imposible" (en Ugalde, 2007: 293) ${ }^{17}$, con respecto a la autora que nos ocupa cabe citar

\footnotetext{
${ }^{17}$ Es preciso señalar que el caso de Francisca Aguirre es controvertido. Tanto por edad (1930), por sus preocupaciones estéticas como por las temáticas que desarrolló en su lírica se ha emparentado a menudo con la generación del 50 (Wilcox, 1992: 65). Sin
} 
el poema titulado "Posguerra" (1999: 138-139), sobre el que volveremos más adelante. Pero, insistimos, historizar (ser en la Historia), implica ir más allá de fechar los poemas. Consiste, más bien, en dotar a la poesía de un valor testimonial a partir de la narración de experiencias:

Si es obvio que la poesía social parte de un realismo, tiene un claro matiz histórico: un aqui y un ahora, y se objetiva narrativamente - notas compartidas con la poesía politica-debe añadirse el carácter testimonial y la intención denunciadora. Ambas cosas, pues el testimonio, por sí solo, no es suficiente. Un poeta no es un mero testigo, ni un notario. Es, además, protagonista: está inmerso como hombre en las circunstancias que impulsan sus poemas y muchas veces las padece (Luis, 2000: 13).

Con respecto al uso de una primera persona en el poema, y la importancia de la autorreferencialidad en este tipo de poesía, esto es, el querer sumir a la poesía en la realidad circundante, arrastra consigo la inmersión de la propia voz poética y sus vivencias, no tanto íntimas sino en relación a la convivencia en sociedad, como modo desde el cual alcanzar una representación popular (García, 2012: 126). Esto ocurre en la mayoría de los poetas sociales. Podemos recordar ejemplos como el poema "Para que yo me llame Ángel González” del poeta homónimo (2004: 15), así como "Barcelona ja no es bona o mi paseo solitario en primavera" de Jaime Gil de Biedma (2006: 121), en el que los detalles y nombres biográficos se mezclan con la Historia colectiva. En el caso de Figuera,

embargo, si nos atenemos a criterios cronológicos no se emparentaría con la poesía social ya que, según Leopoldo de Luis, la poesía social comenzó a extinguirse a partir de mediados de los 60 (2000: 223-224) y Francisca Aguirre no publicó su primer libro, Ítaca, hasta 1972. A este respecto, es preciso señalar que el hecho de que no publicara hasta entrada la cuarentena, lo cual la ha llevado a estar en este limbo generacional, no es sólo una peculiaridad de Aguirre sino que también le ocurrió a la propia Figuera, quien no publicó hasta los 46 años (Wilcox, 1992: 66; Ugalde, 2007: 19). Este breve apunte pretende subrayar que la trayectoria intelectual de las mujeres poetas estuvo marcada por los condicionantes de la época que estamos estudiando. 
la elección de permanecer en el país y observar su realidad cotidiana, en lugar de exiliarse, marcaron su poesía de manera directa, de modo que el contacto con la realidad histórica del momento constituyó un material poético valiosísimo para su trabajo, tal como ella misma declaró:

He preferido siempre quedarme en mi tierra. Fuera, acaso, hubiera tenido más libertad para decir, pero me hubiera sentido sin raices y no creo que mi poesía hubiera ganado nada con ello. Aquí, tocando la tierra nuestra, amándola y sufriéndola, he escrito mis poemas que también tienen sus raices en este mundo que es el nuestro y el de hoy (en Zabala, 2003: 255).

\subsection{Poesía como comunicación y recepción masiva}

Los poetas sociales concebían principalmente la poesía como un acto de comunicación. Sin ir más lejos, Celaya, considerado máximo representante de esta posición, defendía ante todo una poesía humanista, cuyo valor residiera en llegar al otro. Esta era la mayor exigencia para lo que se consideraba una poética de lectores, en versos de Fuertes: "No es todo hacer una poesía para el pueblo / sino un pueblo para la poesía, / por eso escribo para el niño / y para el adolescente / que pronto serán el nuevo pueblo decente" (1981a: 107). Además, existía una conciencia de que la poesía había de ser un instrumento para transformar el mundo, como bien remarca de nuevo Celaya en su famosísimo poema "La poesía es un arma cargada de futuro" (1976: 93). Se trataba por tanto de abrirse a la sociedad como un obrero de la palabra: "Cantemos como quien respira. Hablemos de lo que cada día nos ocupa. [...] La Poesía no es un fin en sí. La Poesía es un instrumento, entre nosotros para transformar el mundo" (en Rubio y Urrutia, en Luis 2000: 94). Se hace evidente que tales poetas tenían conciencia de ser un trabajador más, lo cual se aleja de la idea de genio artístico heredado del Romanticismo con el que se ha tendido a identificar al poeta (García, 2012: 32-33, 210), entre ellos la propia Figuera, quién 
hablaba así de su propia poesía:

Crear belleza pura, inútil, y cruel en su exclusividad, ya no es bastante. Hay que hacer algo más con la poesía, que es mi herramienta [...] Por eso mi poesía de hoy grita con el dolor de todos y denuncia con la rabia de todos. Y pretende estar con todos los que saben su dolor y los que lo ignoran; los que buscan y los que caminan a ciegas. $Y$, si no puede salvarlos, al menos puede caminar con ellos. No me importa si mi poesía es, por lo circunstancial, por lo concreta e impura, perecedera. Si un solo hombre de mi tiempo se siente por ella comprendido $y$ acompañado, consolado y estimulado, ya no habrá sido inútil (en Luis, 2000: 228-229).

Otro de los presupuestos más destacados de este movimiento era el interés de dirigirse a un público amplio, popular, con el que identificaban su poesía como ya estudiamos anteriormente con respecto a la noción de poética de la comunicación.

\subsection{Recursos estilísticos: oralidad e ironía}

Además de lo dicho, podemos señalar dos de los recursos estilísticos más notables de la poesía de postguerra: la oralidad y la ironía. Primeramente, nos detendremos a explicar y ejemplificar en qué consistía la oralidad, pues tal cómo señalábamos anteriormente, muchos de los poetas sociales pretendían reflejar en su poesía la realidad circundante a la vez que deseaban llegar a un público lector amplio (García, 2012: 123), razón que les llevó a utilizar un lenguaje que imitara la oralidad como modo de dotar a sus composiciones de verosimilitud. Entre los recursos retóricos más utilizados para conseguir el efecto de oralidad destacan el uso de palabras vulgares o cotidianas y la deconstrucción y reelaboración de frases hechas (García, 2012: 127). Una de las poetas sociales que más se ha servido 
de la reescritura de expresiones idiomáticas ha sido Gloria Fuertes, por citar algunos de los ejemplos más conocidos destacan el poema "Cabra sola” (1981a: 212), que comienza con el verso: "Hay quien dice que estoy como una cabra", y que coloquialmente significa haber perdido la cordura (Ramón, 2006: 6). También destaca el título del poemario Mujer de verso en pecho (1995) que juega con la frase hecha hombre de pelo en pecho y que es sinónimo de hombría. En esta misma línea Ángela Figuera también juega con este tipo de referencias en versos como: "Mujer de carne y verso me declaro" del poema "Aunque la mies más alta dure un día" (1999: 289) en lugar de la expresión idiomática de carne y hueso, así como el verso "no tengo siquiera dónde caerme viva" de "Pobre" (1999: 148-149) que altera la locución no tener dónde caerse muerto.

El otro gran recurso retórico de la poesía social fue la ironía, que en gran medida se utilizó como estrategia para eludir la censura ya que mediante el humor se hacían denuncias explícitas de una situación social trágica. Así lo declaraba el poeta Ángel González:

Han sido bastantes los críticos que relacionaron mi poesía con la ironía -otro rasgo generacional. El uso de la ironía fue, en principio, otro imperativo de la situación. Como es sobradamente sabido, los textos irónicos exigen que el lector invierta el recto significado de las palabras; operación mental que, aunque sencilla, desbordaba de hecho la capacidad intelectiva de muchos censores, primera ventaja de un procedimiento que implica además la relación y consiguiente comparación evaluativa de dos puntos de vista opuestos. Así, el procedimiento resultaba doblemente útil: permitía burlar las normas vigentes en materia de censura, y era de una gran eficacia crítica (en Pueo, 2007: 112).

Este recurso fue muy empleado por diferentes poetas sociales. El propio González lo cultivó en numerosos ejemplos, entre los que podemos 
señalar el poema "Discurso a los jóvenes" (2004: 115), donde encontramos sentencias como esta: "Si alguno de vosotros pensase / yo le diría: no pienses". También Gloria Fuertes ha sido un ejemplo paradigmático de poeta que mediante el humor critica una sociedad injusta en especial para la mujer. Valga como muestra el poema "Es obligatorio tener mitos" (1981b: 136): "Es obligatorio no asomarse a la ventanilla, / porque tienes que estar vivo si organizan la guerra [...] Llevar medias en los templos, / tener bastantes hijos [...] Es obligatorio todo esto, / y encima te prohíben escupir en el suelo". En última instancia, cabe referir que Ángela Figuera también mostró grandes dosis de ironía con el mismo fin que sus compañeros. El citado poema "Posguerra" (1999: 138-139) da buena prueba de ello. Comienza así: "Alegraos, hermanos, porque vivos seguimos. / Verticales, calientes sobre tierra segura / persistente al estruendo y a la dura piqueta [...] Alegraos, hermanos, porque es bueno quedarse [...] Porque estamos enjutos transcurrido el diluvio, / alegrémonos, hijos".

\subsection{Epílogo: Las contradicciones de la poesía social}

Sin embargo y pese a las buenas voluntades de los poetas la contradicción anidaba entre sus presupuestos. La primera de ellas es sencillamente que la recepción no fue tan masiva como la primera generación de poetas sociales esperaba y, por lo tanto, hubo de matizarse el alcance que finalmente tuvo con respecto a las expectativas iniciales. Así advertía Leopoldo de Luis en el prólogo de la antología estudiada las posibles confusiones a las que los términos podían llevar:

No caigamos, sin embargo, en la fácil objección de la no popularidad de la poesía. Poesía social y poesía popular no son la misma cosa. Que esta poesía vaya, en potencia, dirigida a las mayorías, que pretenda asumir el dolor de los otros, no quiere decir que haya de realizar un arte inmediatamente asequible a las masas [...] Es cuestión de advertir la necesidad de no 
mezclar el propósito y el logro de la poesía traída a este libro con el problema del arte de masas. En todo caso, su relación consiste en que la poesía social puede hacer suya -y de hecho lo hace muchas veces-la denuncia de un mísero estado cultural del pueblo, de una paupérrima atención de la sociedad por los problemas educacionales (2000: 60).

Así mismo, la esperanza que residía en la capacidad transformadora del "arma cargada de futuro" de Celaya chocó contra el muro de la realidad y posteriormente tuvo que aceptar las propias contradicciones que albergaba su poesía. En palabras del propio poeta:

No me daba cuenta de todo lo que implicaba, aunque era evidente. No veía, por ejemplo, que esa transformación de la que formaba parte el acceso a esa inmensa mayoría, sin la cual no sería nada nuestra poesía salvo bizantinismo, no podía lograrse con sólo una revolución literaria (en Rubio y Urrutia, en Luis, 2000: 113).

Quizá por ello, la autora que estudiamos siempre se mostró recelosa de esta supuesta capacidad de transformación de la poesía. Tal como vimos antes en su poética, ella era consciente de las limitaciones de su propia poesía, lo cual la llevaba a conformarse con poder, al menos, comprender a uno solo de sus contemporáneos (en Luis, 2000: 228-229). Aunque Figuera es considerada una poeta social (Payeras Grau, 2002: 27), tanto por la temática y la estética de sus composiciones, muy en la línea de los presupuestos poéticos de Celaya y Otero, por nombrar los autores sociales más señeros, así como por su participación en antologías generales de poesía social ${ }^{18}$, entre ellas la del propio Leopoldo de Luis. No

\footnotetext{
${ }^{18}$ Entre otras antologías de poesía social en las que se ha incluido a Figuera podemos señalar 13 poetas testimoniales (2000) de Segismundo Lince. A este respecto cabría matizar que no siempre se la incluyó en obras generales con estos presupuestos, nos referimos
} 
obstante, cabe ahondar en los motivos por los que la poeta puso de relieve las propias contradicciones de la poesía social.

En primer lugar, la concepción de que la poesía pudiera llegar a ser un fenómeno de masas pecaba de ingenua, hecho sobre el que ironizaron los detractores de este movimiento (García, 2012: 125). De manera que frente a la candidez de sus compañeros y amigos, Figuera más realista afirmaba lo siguiente: "Esa dedicatoria 'A la inmensa mayoría' me parece de perlas, pero mucho temo que no pase de una intención por su parte ${ }^{19}$. La inmensa mayoría no se entera de nada de lo que a poesía se refiere ( $\mathrm{Ni}$ de otras muchas cosas tampoco)" (en Zabala, 2003: 256). En esta misma línea su poema "Epílogo a Blas de Otero" (1999: 163-165) da cuenta de su progresivo alejamiento con respecto a los presupuestos poéticos de sus compañeros:

Tú querías correr a salvarnos. Querías

( $\tan$ fieramente humano $)^{20}$ guardarnos las espaldas,

protegernos la frente contra viento y marea,

contra viento y destino. Y no sabías cómo.

$[\ldots]$

Y yo llegué a decirte: Mejor fuera el silencio.

Mejor fuera callarse. Licenciar la metáfora.

$Y$ a ver si a duras penas o a duras alegrías

abrimos un camino al cabo de la calle.

particularmente a la Antología consultada de la joven poesía española (1952) de Francisco Ribes, y esta exclusión se debió, tal como han señalado críticas como Alonso Valero (2017: 102-103) y Rodríguez Cacho (2017: 310), principalmente a una cuestión de discriminación por razones de género.

${ }^{19} \mathrm{Con}$ la referencia que Figuera cita en sus declaraciones está aludiendo conscientemente al poema de Blas de Otero titulado "A la inmensa mayoría" (2013: 227), al que hemos remitido anteriormente. De manera que Figuera al citarlo lo que hace en realidad es alejarse de los presupuestos que su compañero de generación propone en dicha composición. ${ }^{20} \mathrm{En}$ el fragmento del verso que hemos resaltado Figuera remite al libro Ángel fieramente humano (1950) de Blas de Otero. 
A este primer rechazo, también podemos sumarle su propia conciencia de género (Arkinstall, 1997: 457). Es decir, aunque se diera el hipotético e improbable caso de que la poesía contribuyera finalmente a transformar la realidad, generalmente los poetas pensaban en términos de luchas de clases (García, 2012: 24), pero no valoraban en su poesía que la desigualdad de género se derivara también de la explotación capitalista y como tal fuera otra (aunque la misma) lacra a abolir. De manera que las propias poetas, entre ellas Figuera, eran muy conscientes de esta doble dificultad, lo cual llegaba a teñir en muchos casos sus creaciones de un fuerte carácter existencialista. En el caso de Figuera esta actitud se radicaliza a partir de El grito inútil (1952) (Wilcox, 1992: 71-72; Payeras Grau, 2002: 31; Zabala, 2003: 251-252). A este respecto, valga señalar algunos versos del poema-pórtico homónimo que dan cuenta de la doble frustración que provoca en el sujeto femenino hablante, ser consciente, que ser mujer y poeta supone un intento de comunicación infructuoso: “¿Qué vale una mujer? ¿Para qué sirve / una mujer viviendo en puro grito? [...] ¿Qué puedo yo, menesterosa, incrédula, / con sólo esta canción, esta porfía / limando y escociéndome la boca?" (1999: 135-136).

Al hilo de esta composición es vital entender que la autora, pese a utilizar la primera persona, no está hablando de sí misma — no estamos ante una autobiografía ficcional- por más paralelismos que podamos encontrar con la vida de la propia escritora, sino que, en sintonía con los presupuestos de la poesía social, construye una máscara ficcional extrapolable a las vivencias cotidianas de las mujeres de su época (Robbins, 2000: 568; Payeras Grau, 2002: 34-35). Las cuales, según los preceptos del franquismo, debían dedicar su vida al trabajo reproductivo, tanto doméstico como afectivo. 


\section{ALIMENTACIÓN Y TRABAJO REPRODUCTIVO EN ÁNGELA FIGUERA}

A veces se olvida - pero no por ello deja de ser cierto - que pese a denominarse autarquía, el régimen de Franco se basó en un modelo socioeconómico capitalista. Es por ello que, cuando analizamos desde nuestras coordenadas actuales la situación de la mujer española de posguerra, hablamos de trabajo reproductivo en lugar de tareas domésticas y alimentarias, aplicándole una perspectiva materialista que tenga en cuenta el marco de producción en el que se daban las mismas. Con ello evitamos para no caer en el juego de la ideología nacionalcatólica, la esencialización del género femenino (Robbins, 2000: 576). También suele pasarse demasiado rápido por otro punto crucial. Es preciso señalar que la relación establecida entre mujer y domesticidad no fue una característica propia del franquismo, impuesta durante la posguerra, sino que ha sido y sigue siendo una constante en la división de tareas de la economía capitalista global:

Con más consistencia se puede afirmar que la fuerza motriz de la economía mundial ha sido la capacidad del capitalismo internacional de apropiarse de las masas trabajadoras globales de campesinos expropiados y de amas de casa, es decir, de la inmensa cantidad de trabajo no contractual, incrementando asi de manera exponencial los porcentajes de extracción de plusvalía [...] El trabajo doméstico fue una creación del capitalismo de finales del siglo XIX, construido en el auge de la industrialización tanto para pacificar a los trabajadores masculinos como para impulsar el cambio de la industria textil a la pesada (en términos marxistas, de la plusvalía absoluta a la relativa) (Federici, 2013: 187-188).

A partir de esta perspectiva es preciso señalar la relación entre alimentación y trabajo afectivo, que se engloba dentro del concepto de 
trabajo reproductivo previamente referido. Según Federici, el trabajo reproductivo se divide a su vez en trabajo doméstico y trabajo de cuidados (2013: 175), es decir, tareas del hogar y trabajo afectivo, siendo este: "aquel que produce o manipula afectos, como las sensaciones gratas o de bienestar, la satisfacción, la excitación o la pasión" (2013: 193). Es preciso señalarlo porque el hecho de vincular trabajo y afectividad desmonta también la ideología esencialista que el régimen franquista impuso a la mujer: "las mujeres son los sujetos centrales del trabajo emocional y de que, aunque este sea un trabajo asalariado de atención al público, en esencia se trata del mismo tipo de trabajo que las mujeres han realizado siempre" (2013: 194).

Llegados a este punto, podemos acudir a la literatura para ver cómo la escritura fue fiel testimonio de la estrecha relación que se estableció entre la mujer y el universo alimenticio, teniendo en cuenta el valor afectivo que la nutrición tiene en nuestra cultura (Rodríguez Cacho, 2017: 308). De este modo, encontraremos múltiples composiciones literarias fechadas entre 1939 y 1965 que reflejan la figura de la mujer como sustentadora del hogar ${ }^{21}$. Desde los conocidos versos de Miguel Hernández: "En la cuna del hambre / mi niño estaba. / Con sangre de cebolla / se amamantaba [...] Una mujer morena / resuelta en luna / se derrama hilo a hilo / sobre la cuna" del famoso poema "Nanas de la cebolla" (1979: 473-476), los reveladores: "La mujer. La de siempre. La mujer de la casa / que tiene el pan y el agua como símbolo" de María Beneyto (en Conde, 1967: 59) pasando por el testimonio poético de Gloria Fuertes: "Aprendí a regatear en las tiendas / y a ir a los pueblos por zanahorias" (1981b: 41-42)22, hasta el retrato costumbrista que la propia Ángela Figuera lleva a cabo de las "Mujeres del mercado" (1999: 142-143), en el que se aborda la doble dimensión, afectiva y doméstica, del trabajo reproductivo:

\footnotetext{
${ }^{21}$ Para esta delimitación temporal nos hemos servido del estudio de Luis (2000: 223-224), previamente citado.

${ }^{22}$ Hemos destacado este verso porque refleja muy bien la tarea generalmente ejercida por la mujer de la búsqueda de alimentos en las incursiones a las zonas rurales durante la posguerra. A este propósito son muy reveladores los testimonios recogidos en Barranquero y Prieto (2003).
} 
Van temprano a la compra. Huronean los puestos.

Casi escarban. Eligen los tomates chafados.

Las naranjas mohosas. Maceradas verduras

que ya huelen a estiércol. Compran sangre cocida

en cilindros oscuros como quesos de lodo

[…]

Siempre llevan un hijo, todo greñas y mocos, que les cuelga y arrastra de la falda pringosa [...]

Van a un patio con moscas. Con chiquillos y perros.

Con vecinas que riñen. A un fogón pestilente. A un barreño de ropa por lavar. A un marido [...]

Que tal vez por la noche, en la fétida alcoba, sin caricias ni halagos, con brutal impaciencia de animal instintivo, les castigue la entraña con el peso agobiante de otro mísero fruto.

De manera que las mujeres retratadas aquí, no sólo ejemplifican cómo se relaciona íntimamente trabajo doméstico y feminidad, desde la compra de alimentos, la preparación de estos y la limpieza, sino que también se aborda el trabajo afectivo en tanto que las figuras femeninas que aparecen en el poema se encargan, además, tanto del cuidado de los hijos como de satisfacer sexualmente al marido que funciona, en último término, como su empleador. En palabras de Federici:

El capital creóal ama decasa para servir al trabajador masculino, fisica, emocional y sexualmente; para criar a sus hijos, coser sus calcetines y remendar su ego cuando esté destruido a causa del trabajo y de las (solitarias) relaciones sociales que el capital le ha reservado. Es precisamente esta peculiar combinación de 
servicios fisicos, emocionales y sexuales que conforman el rol de sirvienta que las amas de casa deben desempeñar para el capital lo que hace su trabajo tan pesado y al mismo tiempo tan invisible (2013: 38).

\subsection{La paradójica resistencia del ángel del hogar}

Sin embargo, la obra de Figuera no se limitó a dibujar la realidad contemplada sino que, como poeta social, reivindicó que las mujeres desde el propio rol materno, en tanto que reproductoras de vida y proveedoras de alimentos y cuidados, adquirieran una posición activa. Siendo conscientes de las contradicciones que desde nuestro horizonte actual esta reivindicación pueda suscitar, consideramos que lo que pretendía Figuera, sabedora igualmente de las restricciones que las mujeres de su generación tenían en tanto que sujetos de derecho, era empoderarlas a partir del único rol que les estaba permitido en la sociedad del momento.

De manera que cuando Figuera utiliza el campo semántico del trabajo para referirse a las tareas domésticas, lo desprende del halo esencialista con que se cargó y lo hace visible, condición indispensable para poder empezar a rebelarse contra él (Federici, 2013: 40). Con respecto a la utilización del campo semántico del mundo laboral en su lírica destacan "Poquita labor" (1999:70), "Los días duros" (1999: 169), del que valga señalar los siguientes versos: "Cómo me di a la lluvia y a los vientos / al fuego del varón y a la tarea / de concebir y de alumbrar con grito" 23 ,

\footnotetext{
${ }^{23}$ A este respecto cabe destacar que, como puede leerse en este poema, del que valga citar también los siguientes versos: "Hoy ya no puedo [...] / Ya no podemos acunar la débil / carne del hijo en un regazo tibio / de raso y plumas: hay que sostenerla / con fuertes manos, apoyarla adrede / en el inquieto suelo, preparando / con firme decisión su andar futuro. / Los días duros se abren a mi quilla.", la mujer española se consagró a la tarea de la reproducción que le fue impuesta, fomentada, a su vez, por medio de las políticas pronatalistas del régimen franquista, para suplir el déficit demográfico existente durante la posguerra. No obstante, como hace notar la poeta, al mismo tiempo la figura de la mujer en tanto que madre sufrió, paradójicamente, una estigmatización contra la cual Figuera, en los últimos versos de esta composición, propone rebelarse. Para ilustrar mejor nuestra
} 
y "Canto a la madre de familia" (1999: 237-238) en el que enumera con exaltación heroica todas las labores que realiza cotidianamente una ama de casa:

Canto a sus manos suaves de lejía

los lunes y los martes,

los miércoles y jueves picadas por la aguja,

quemadas cada viernes por la plancha,

ungidas por el ajo y la cebolla

[...]

Canto a la madre de familia

a las ocho de la mañana

distribuyendo cautamente

la leche azul del desayuno

en los tazones de asa rota.

Sin olvidar tampoco alcanzar con su canto a todo el colectivo explotado en poemas como "Donde veas" (1999: 275-276) y "No quiero" (1999: 279-280), donde al reunir en un mismo espacio las reivindicaciones tanto del ama de casa como del trabajador de la fábrica está mostrando que la explotación laboral de ambos tiene la misma procedencia.

En segundo término, lo que hace Figuera en su poesía es crear comunidad a partir de la reivindicación de la capacidad reproductora de la mujer, traduciendo esta cualidad como sinónimo de poder en lugar de

\footnotetext{
lectura nos serviremos de las palabras de Arkinstall (1997: 452-459): "Figuera's representations of the maternal situate her within a Spanish tradition of gynopoetics that has frequently availed itself of such configurations for subversive purposes [...] the mother as cultural construction offers Figuera specifically a vital manoeuvrability within a patriarchal society whose concept of nationhood is sustained by its own agenda with regard to the maternal body. Mothers, according to Francoist ideologues, are both the cause of Spain's degeneration and the hope for her regeneration. In order to encourage women to fullfil this so-called sacred mission and to restore demographic growth after the Spanish Civil War, pronatalist policies, which perceived the patriarchal family as "the primary social unit of Spanish society', were developed in the early years of Franco régime".
} 
subyugación, como estaba siendo durante el franquismo (Payeras Grau, 2002: 36-37; Zabala, 2003: 261). En esta línea podemos nombrar los poemas: "Rebelión" (1999: 143-144), "Mundo concluso" (1973: 193194), "Madres" (1999: 176) y "Destino" (1999: 185).

Para concluir nos detendremos en el poema "Madres" (1999: 176178), en el que Figuera, a la manera de una Lisístrata contemporánea, incita al colectivo femenino a que tome conciencia de su capacidad de decidir sobre su propio cuerpo, en tanto que reproductor, y sobre el destino de sus hijos, y en segundo lugar, reflejando la importancia de esta decisión en un contexto política y económicamente desfavorable:

Madres del Hombre, úteros fecundos,

Hornos de Dios donde se cristaliza

el humus vivo en ordenados moldes

[...]

Y luego, ¿qué?... Cumplisteis la tarea.

[...]

¿Qué campos abonados

con aceros y pólvoras

verán crecer la espiga suficiente

al hambre de su boca sin pecado?

[...]

Madres del mundo, tristes paridoras,

gemid, clamad, aullad por vuestros frutos.

Es interesante observar cómo Figuera se desprende del tono autobiográfico de su primera poesía transcendiendo su testimonio de la esfera personal a la colectiva, para así crear una comunidad de mujeresmadres (Quance, 1999: 17). De manera que unidas las mujeres puedan ejercer una resistencia justamente a partir de la apropiación de los distintivos con los que el franquismo las había oprimido. Ha de precisarse que este tipo de resistencia femenina no es algo propio del contexto de la 
posguerra española, sino que ha venido funcionando históricamente como modelo de reapropiación de la identidad femenina:

Pese a las guerras, las crisis económicas y las devaluaciones, mientras que el mundo se caía a pedazos a su alrededor, las mujeres han continuado plantando maiz en campos abandonados, cocinando alimentos para venderlos en los arcenes de las carreteras, creando cocinas comunales [...] interponiéndose de este modo a la mercantilización de la vida y dando pie a procesos de reapropiación y recolectivización de la reproducción, indispensables si queremos recuperar el control sobre nuestras vidas (Federici, 2013: 180).

Tan sólo recordemos algunos ejemplos notables como las madres de la Plaza de Mayo, las madres contra la droga, contra la represión, contra la guerra, contra la Mafia y las proletarias/indígenas de Chile que, tras el golpe militar de 1973, se unieron para garantizar la alimentación de sus familias mediante la organización de cocinas comunales —ollas comunes-(Zabala, 2003: 265-266; Federici, 2013: 149-150).

\section{CODA: "SOLA NO ESTÁS" 24}

A modo de epílogo a estas notas, queda señalar muy brevemente que, pese a que el hambre y el universo femenino fueron silenciados durante los años de la posguerra, nuestras palabras han tratado de repensar nuestra Historia y nuestro canon poético para poder otorgar a estas dos ausencias el lugar que merecen. Y logren también, estas palabras, hacer (re)descubrir que no sólo

\footnotetext{
${ }^{24} \mathrm{El}$ subtítulo de este epígrafe "Sola no estás" hace referencia al poema homónimo de Ángeles Mora, en Ficciones para una autobiografía (2015: 26-27), dedicado a la también poeta Juana Castro y cuyos versos concentran la voluntad de esbozo con el que cerramos este trabajo: "No es cuestión de palabras, / es un rumor de fondo / queriendo aparecer. Se entrecruzan las voces [...] / Has de saber qué dicen esas voces / que ya no se conforman, / mujeres que callaron tanto tiempo, / razones que traen luz: para nunca estar solas".
} 
se pasó hambre en España durante largos y oscuros años, que no sólo las mujeres desde sus cocinas trataron de paliarla, sino que hubo tantas, entre ellas Gloria Fuertes, Francisca Aguirre, Susana March, Angelina Gatell, María Beneyto y la propia Ángela Figuera, que la cantaron, a veces para denunciarla, otras para crear comunidad y, en última instancia, pensando, quizás, que hoy las leeríamos nosotros.

\section{REFERENCIAS BIBLIOGRÁFICAS}

ABELLA, R. (1978). Por el imperio hacia Dios. Crónica de una posguerra (1939-1955). Barcelona: Planeta.

ABDELAZIM, R. A. (2017). “Ángela Figuera y Carmen Conde en tres temas". AnMal Electrónica 42, 76-101.

ALDARACA, B. A. (1992). El ángel del hogar: Galdós y la ideología de la domesticidad en España. Madrid: Visor.

ALMODÓVAR, M. Á. (2003). El hambre en España. Una historia de la alimentación. Madrid: Oberón.

ALONSO, D. (1946). Hijos de la ira. Madrid: Espasa-Calpe.

ALONSO VALERO, E. (2016). "Mujeres poetas bajo el franquismo". Cuadernos Hispanoamericanos 793-794, 22-33.

(2017). "Compromiso para una guerra y bajo una dictadura: antologías y canon”. En El compromiso en el canon. Antologías poéticas españolas del último siglo, M. Á. García (ed.), 79-109. Valencia: Tirant Humanidades.

ARKINSTALL, C. (1997). "Rhetorics of Maternity and War in Ángela Figuera's Poetic Work”. Revista Canadiense de Estudios Hispánicos 21, 457-478.

(2009). "The Spanish Civil War and Franco Dictatorship: History as Trauma and Wound in Ángela Figuera's Poetic Work". En Histories, Cultures, and National Identities: Women Writing in Spain, 18771984, C. Arkinstall (ed.), 85-139. Lewisburg: Bucknell University 
Press.

ASCUNCE, J. Á. (1997). “La poesía social. Años 50 en adelante”. En La poesía de postguerra (I). Historia de la Literatura Española, R. De la Fuente (ed.), 117-253. Madrid-Gijón: Júcar.

BARCIELA, C. (ed.) (2003) Autarquía y mercado negro: el fracaso económico del primer franquismo, 1939-1959. Madrid: Crítica

BARRANQUERO TEXEIRA, E. y PRIETO BORREGO, L. (2003). Así sobrevivimos al hambre: estrategias de supervivencia de las mujeres en la postguerra española. Málaga: Servicio de Publicaciones de la Diputación de Málaga.

BLÁZQUEZ VILAPLANA, B. (2016). "Pinceladas sobre una poeta española: Ángela Figuera Aymerich". Cuadernos Hispanoamericanos 793-794, 34-43.

BOSCH, R. (1962). "La poesía de Ángela Figuera. El tema de la maternidad”. Ínsula: Revista de Letras y Ciencias Humanas 186, 5-6.

CAPUCCIO, B. L. (1993). "Hambre y poesía: una breve biografía de Gloria Fuertes”. Anales de la Literatura Española Contemporánea 18, 323-344

CASANOVA, J. (2013). España partida en dos: breve historia de la Guerra Civil española. Barcelona: Crítica.

CELA, C. J. (1951). La colmena. Buenos Aires: Emecé.

CELAYA, G. (1976). Itinerario poético. Madrid: Cátedra.

CONDE, C. (ed.) (1947). Mujer sin Edén. Madrid: Jura.

(1967). Poesía femenina española (1939-1959). Barcelona: Bruguera.

CUENCA TORIBIO, J. M. (2008). Nacionalismo, franquismo y nacionalcatolicismo. Madrid: Actas.

FEDERICI, S. (2013). Revolución en punto cero. Trabajo doméstico, reproducción y luchas feministas. Madrid: Traficantes de sueños.

FIGUERA, Á. (1999). Obras completas. Madrid: Hiperión.

FUERTES, G. (1981a). Historias de Gloria. Humor, amor y desamor. Madrid: Cátedra. 
(1981b). Obras incompletas. Madrid: Cátedra.

GARCÍA, M. Á. (2012). La literatura y sus demonios. Leer la poesía social. Madrid: Castalia.

GIL DE BIEDMA, J. (2006). Las personas del verbo. Barcelona: Galaxia Gutenberg.

GONZÁleZ, Á. (2004). Palabra sobre palabra. Barcelona: Seix Barral. GRAHAM, H. (1996a). "Gender and the State: Women in the 1940s". En Spanish Cultural Studies: An Introduction. The Struggle for Modernity, H. Graham y J. Labanyi (eds.), 182-195. Oxford: Oxford University Press.

(1996b). "Popular Culture in the Years of Hunger". En Spanish Cultural Studies: An Introduction. The Struggle for Modernity, H. Graham y J. Labanyi (eds.), 237-245. Oxford: Oxford University Press.

HERNÁNDEZ, M. (1979). Obra poética completa, L. de Luis y J. Urrutia (eds.). Madrid: Alianza.

JURADO MORALES, J. (2014). "El discurso patriarcal en la poesía femenina del primer franquismo". Signa. Revista de la Asociación Española de Semiótica 23, 525-544.

LARA-KUHLMAN, L. E. (2012). "Lenguaje, Corporealidad e Identidad en la obra de Ángela Figuera Áymerich". Utah Foreign Language Review 20, 87-104.

LINCE, S. (2000). 13 poetas testimoniales. Madrid: Edaf.

LUIS, L. de (ed.) (2000). Poesía social española contemporánea. Antología (1939-1968), F. Rubio, y J. Urrutia (eds.). Madrid: Biblioteca Nueva.

MARTÍN GAITE, C. (1987). Usos amorosos de la posguerra española. Barcelona: Anagrama.

MORA, Á. (2015). Ficciones para una autobiografía. Madrid: Bartleby.

NASH, M. (2015). "Vencidas, represaliadas y resistentes: las mujeres bajo el orden patriarcal franquista”. En Cuarenta años con Franco, J. Casanova (ed.), 191-228. Barcelona: Crítica. 
NÚÑEZ DÍAZ-BALART, M. (2003). Mujeres caídas: prostitutas legales $y$ clandestinas en el franquismo. Madrid: Oberon.

OTERO, B. (2013). Obra completa (1935- 1977). Barcelona: Galaxia Gutenberg.

PAYERAS GRAU, M. (2002). "Ángela Figuera: Mujer de carne y verso". En El linaje de Eva. Tres escritoras de postguerra: Ángela Figuera, Celia Viñas y Gloria Fuertes, M. Payeras Grau, 17-60. Madrid: Sial.

(2008). "La voz reprimida de la mujer en las generaciones poéticas de posguerra". Texturas 8, 171-180.

PRESTON, P. (2011). El Holocausto español: odio y exterminio en la Guerra Civil y después, C. Martínez Muñoz y E. Vázquez Nacario (trads.). Barcelona: Debate.

PUEO, J. C. (2007), “Espía de palabras’. Ironía y poética de Ángel González". Tropelías. Revista de Teoría de la Literatura y Literatura Comparada 3, 111-130.

QUANCE, R. (1999). "En la casa paterna”. En Obras completas, A. Figuera, 15-25. Madrid: Hiperión.

RAMÓN, E. (2006). "Gloria Fuertes: la poesía como alternativa femenina ante lo establecido". Espéculo. Revista de estudios literarios 32, $1-15$.

REYZÁBAL RODRÍGUEZ, M. V. (2009). “Ángela Figuera: la maternidad, experiencia exclusiva". Zurgai. Euskal herriko olerkiaren aldizkaria: Poetas por su pueblo 12, 12-16.

RIBES, F. (1952). Antología consultada de la joven poesía española. Valencia: Mares.

RICHARDS, M. (1998). Un tiempo de silencio: La guerra civil y la cultura de la represión en la España de Franco, 1936-1945, T. de Lozoya (trad.). Barcelona: Crítica.

ROBBINS, J. (2000). "La mujer en el umbral. La simbología de la madre en la poesía de Ángela Figuera". Anales de La Literatura Española Contemporánea 25, 557-585. 
RODODERA, M. (1962). La plaza del diamante. Barcelona: EDHASA. RODRÍGUEZ CACHO, L. (2017). "Mujeres y 'exilio interior': a propósito de Ángela Figuera”. Tropelías. Revista de Teoría de La Literatura y Literatura Comparada 2, 306-315.

RODRÍGUEZ NÚÑEZ, V. (2001). "Género, alteridad y poesía en Belleza Cruel, de Ángela Figuera”. Revista Hispánica Moderna 54, 140153.

UGALDE, S. K. (ed.) (2007). En voz alta. Las poetas de las generaciones de los 50 y los 70. Antología. Madrid: Hiperión.

(2009). "Transgredir límites: "Versos que salieron a correr mundo"”. Zurgai. Euskal herriko olerkiaren aldizkaria: Poetas por su pueblo 12, 76-80.

VILA-BELDA, R. (2008). "Pan y versos: hambre y subversión en la poesía de Gloria Fuertes”. Bulletin of Spanish Studies 85, 193-215.

ZABALA, J. R. (2003). “Ángela Figuera Aymerich. Cuando la poesía no basta: activismo poético en defensa del ser humano". En Españolas del siglo XX: promotoras de la cultura, M. J. Jiménez Tomé y I. Gallego Rodríguez (eds.), 245-283. Málaga: Centro de Ediciones de la Diputación de Málaga.

WILCOX, J. C. (1992). “A Reconsideration of Two Spanish Women Poets: Angela Figuera and Francisca Aguirre". Studies in 20th \& 21st Century Literature 16, 65-92.

Recibido el 26 de abril de 2018.

Aceptado el 24 de mayo de 2018. 
